\title{
Economics of fragmented land for vegetable growers in Skopje and the Southeastern region of the Republic of Macedonia
}

\author{
Jordan Hristov, Hans Andersson and \\ Dragan Gjosevski
}

\begin{abstract}
This paper examines the influence of land fragmentation on the value of vegetables produced in the Skopje and Southeastern regions of the Republic of Macedonia. The analysis uses models such as a Cobb-Douglas production function as well as a General Linear Model. The findings support a negative and statistically significant impact of land fragmentation on the productivity and profitability of vegetable production in the study area. A reduction from 0.43 to 0.2 of the Simpson index, on average, increases vegetable production by approximately $7.06 \%$.

However, the results reveal that land is of somewhat less importance due to the opportunity to use greenhouse technology. The results based on the linear model reveal that the introduction of greenhouse technology increases the value of production by around 32\%. Nevertheless, appropriate policies ought to promote successful land consolidation further.
\end{abstract}

Keywords: land fragmentation; vegetable production; land consolidation; Simpson index; Macedonia

Jordan Hristov (corresponding author) and Hans Andersson are with the Department of Economics, Swedish University of Agricultural Sciences, Box 7013, 75007 Uppsala, Sweden. E-mail: jordan.hristov@slu.se.Dragan Gjosevski is with the Faculty of Agricultural Sciences and Food, University Ss. Cyril and Methodius, Skopje, Macedonia.

Land is an essential natural resource, both for the survival and prosperity of humanity and for the maintenance of global ecosystems (FAO, 2008). Land fragmentation, a common phenomenon in agriculture, particularly in developing and transition countries (Swinnen et al, 2004) may be defined as the practice of farming a number of spatially separated plots of land owned or rented by the same farmer (McPherson, 1982). In the literature, researchers have classified the causes of land fragmentation into two broad categories: supply-side and demand-side causes (Bentley, 1987). The supply-side causes refer to an exogenous imposition on farmers of a pattern of land areas as a result of inheritance laws, population pressure and scarcity of land (McPherson,
1982). Failure of land markets and state laws can also be one of the major causes of fragmentation, where transactions in land are restricted. The second category reflects varying degrees of fragmentation chosen positively by farmers in order to reduce risk from natural disasters (such as floods, droughts, fires and other risks), to promote crop diversification, as well as to ease the allocation of labour over cropping seasons (Fenoaltea, 1976; Ilbery, 1984; Tan, 2005).

Blarel et al (1992) argue that land fragmentation has also had negative effects, including higher costs (labour, transportation, etc), increasing negative externalities (such as reduced opportunities for irrigation and soilconservation investments, access routes), loss of land due 
Table 1. Research on the effects of land fragmentation on productivity.

\section{Study}

\section{Results}

Holding size

Blakie and Sadeque (2000)

Wan and Cheng (2001)

Wu et al (2005);

Tan (2005)

Sherlund et al (2002)

Parikh and Shah (1994); Wadud and White (2000)

\section{Parcel size}

Blarel et al (1992)

Jabarin and Epplin (1994)
Serious problem in increasing productivity in Nepal, India and nearby regions

Limit in productivity in China

Positive effect on rice production in China

Increased number of plots positively affects rice production in Côte d'Ivoire

Reduces efficiency in rice production in Pakistan and Bangladesh

Parcel size in Ghana and Rwanda either had an insignificant effect on yield or was negatively related to yield

Increase in average plot size has a small but noteworthy negative effect in northern Jordan

to borders and greater possibilities for causing disputes between neighbouring farmers. According to Wan and Cheng (2001), land fragmentation causes resource disutility and underutilization in which it is difficult to apply new technologies of agricultural modernization and reap economies of scale when farms are small and fragmented. Small fragmented farms may also prevent farmers from cultivating more profitable crops (fruit crops). Finally, Blarel et al (1992) report that land fragmentation tends to constrain the efficient delivery of support services because the costs of extension and land improvement services rise with the increasing number of land parcels.

Agricultural land in the Republic of Macedonia amounts to 1,275,000 ha (1999-2004 average), or approximately $50 \%$ of Macedonia's total territory, whereas vegetable production amounts to around $23 \%$ of the total value in its agricultural crops (MAFWE, 2007). According to Swinnen et al (2004), 'agricultural land in Macedonia is extremely fragmented'. Partial inheritance has been cited as causing or contributing to involuntary fragmentation. This is the main factor causing land fragmentation in Macedonia. The division of parcels continues in practice due to differences in land quality and location. In the small-scale private agricultural sector, the most common and frequently cited disadvantages of fragmentation include 'increased labor and transportation costs, land lost to border markings and access roads, and difficulty in accessing land parcels' (Melmed-Sanjak et al, 1998).

Therefore, land fragmentation may be perceived as a major obstacle for vegetable producers in Macedonia, which may well result in reduced competitiveness, plus economic costs in terms of lower agricultural productivity, thus prohibiting proper land management and sustainable agricultural development. Table 1 summarizes international research on the effects caused by land fragmentation on productivity.

\section{Study aim}

The aim of this study was to examine how highly fragmented land affects productivity and profitability on farms. In most of the literature conducted in relation to land fragmentation, the issue of the magnitude of the impact is rarely reported. In addition, the role of specific technologies is typically not examined. Hence, due to the importance of vegetable production in the region and in Macedonia itself, this study provides insights into the current degree of fragmentation and how this affects the economic performance of small-scale private vegetable farms. By understanding the advantages and disadvantages of fragmentation, suggestions for changes in land policy may be identified.

\section{Analytical framework}

\section{Data collection methods}

The secondary data collection was conducted on smallscale producers in two regions: the Skopje and Southeastern regions, areas where vegetable production is important. Data collection was undertaken between February and March 2009 through visits to the National Extension Agency (NEA) regional offices in Skopje and Gevgelija. The sampling approach was not random, but farms were chosen by advisers employed in the NEA since they were directly involved in data collection and were familiar with the issues regarding data quality. The quality of the data collected by the NEA was ensured by the Farm Monitoring System (FMS). The farm sizes and crops grown differ between the samples. Table 2 summarizes the approach used for this research.

\section{Model specification}

Two models were specified in order to assess the impact of land fragmentation on vegetable production: namely the Cobb-Douglas (CD) and General Linear Model (GLM) specifications. A CD production function was adjusted to a multiple inputs $C D$ regression with the following form:

$$
Y_{i t}=\beta_{0} K_{i t}^{\beta_{1}} A_{i t}{ }^{\left(\beta_{2}+\alpha_{2} S I_{i t}\right)} O I_{i t}^{\beta_{3}} L_{i t}^{\beta_{4}} D G_{i t}^{\beta_{5}} \exp ^{\varepsilon_{i t}}
$$

where for farm $i$ at period $t, Y$ is the value of farm output; $\beta_{0^{\prime}} \ldots \beta_{5^{\prime}} \alpha_{2}$ are parameters to be estimated; $K$ is the capital services cost; $A$ represents land (in ha); $S I$ is the Simpson index (land fragmentation); OI represents other inputs (seeds, fertilizers, chemicals ...); $L$ is labour cost; $D G$ is the dummy for greenhouses $(1=$ if the farmer owns a greenhouse, 0 otherwise); $\varepsilon$ is the error term; and $\exp$ designates the exponential function.

Most crops are grown in the open field, under plastic tunnels or in greenhouses and include tomatoes, cucumbers, peppers, cabbages, potatoes, watermelons and carrots. The capital services cost variable $(K)$ was obtained by the following calculation: capital services $=$ depreciation rate $*$ present value of building + depreciation rate $*$ present value of equipment + fuel costs + cost for hired mechanization service. The depreciation rates used in the calculation are summarized in the Appendix. Machinery maintenance costs were not taken into consideration since the majority of the annual farm 
Table 2. Research method used.

\begin{tabular}{llll}
\hline Study location and period & Number of farms & Sampling approach & Number of visits \\
$\begin{array}{l}\text { Skopje, Gevgelija, Radovis and } \\
\begin{array}{l}\text { Strumica, 2004-07 } \\
\text { Vegetable producers }\end{array}\end{array}$ & $\begin{array}{c}\text { Not random sample } \\
(28)\end{array}$ & $\begin{array}{c}\text { Several visits to NEA } \\
\text { regional offices in Skopje } \\
\text { and Gevgelija }\end{array}$ & $\begin{array}{c}\text { NEA annual farm } \\
\text { report }\end{array}$ \\
\hline
\end{tabular}

reports did not include this information. Regarding the land variable $(A)$, the actual acreage was computed by considering double cropping. However, the number of observations in which double cropping existed was relatively minor compared with the overall farm size: that is, it amounted to around $0.06 \%$ compared with the singlecropping acreage. According to Blarel et al (1992), the two most popular indicators of land fragmentation are the Januszewki index and the Simpson index (SI). To assess the degree of fragmentation, the Simpson index was used:

$$
S I=1-\frac{\sum_{i=1}^{n} a_{i}^{2}}{A^{2}}
$$

where $a_{i}$ is the area of the $i$ th plot and $A$ is the farm size. The Simpson index is bounded between 0 and 1 where a zero value indicates complete land consolidation. One limitation of the Simpson index is that it does not take distance and plot shape into account.

It is apparent that total vegetable output is affected by a set of specific factors. To mitigate the problems of multicollinearity (using the 'collin' test in STATA software; Chen et al, 2011)), several of the most important inputs are summed in one variable. The 'other inputs variable' (OI) in the production function is a summation of seed cost, fertilizers and chemicals costs, as well the cost for covers used for the plastic tunnels, packaging and irrigation. The labour input (L) is obtained as the sum of the family labour costs and the hired labour costs. A summary of the descriptive statistics for the variables used in the production function is presented in Table 4. In addition to the CD production function, the General Linear Model (GLM) was used, since this also utilizes regression analysis. It is defined as follows:

$$
y_{i t}=a+b K_{i t}+c A_{i t}+d S I_{i t}+f O I_{i t}+g L_{i t}+h D G_{i t}+e_{i t}
$$

such that $y_{i t}$ is the value of the response variable for farm $i$ at period $t ; b, c, d, f, g$ and $h$ are parameters for the corresponding variables defined in equation (1); and $e$ is the error term.

The expected impacts (anticipated signs) of the explanatory variables on the total production are given in Table 3. According to the literature, a larger value of the Simpson index is expected to decrease production, since modern agricultural technologies are more complex to use on fragmented parcels. However, as the literature reveals, due to the demand-side causes, it may also increase production through proper risk management strategies and facilitating labour use. Hence, the impact of the Simpson index may be ambiguous. By increasing the capital services of the farm, total production is expected to increase. However, due to the linkage between capital
Table 3. Anticipated signs of the variables included in the model based on the literature.

\begin{tabular}{lc}
\hline Explanatory variables & Expected sign \\
Simpson index & $-/+$ \\
Farm size & + \\
Capital services & $-/+$ \\
Other inputs & + \\
Labour & + \\
Dummy variable for greenhouse & \\
$(=1$ if the farmer owns one $)$ & + \\
\hline
\end{tabular}

services and mechanization and the ability to apply the technology properly due to land fragmentation, this variable may be indistinguishable. Moreover, owning a greenhouse is expected to increase production, because the farmer is able to grow early spring crops under controlled conditions. These crops are highly valued in the Macedonian market.

\section{Empirical findings}

\section{Results}

Before presenting the evidence of fragmentation, Table 4 provides some additional insights into the variables used in the empirical model. From this, it is noticeable that there is a large variation in total earnings from vegetable production, ranging from MKD2,710,800 to MKD13,000 (Macedonian denar (MKD) 61.5623 = €1; NBRM, 2011), mainly due to the ability of farmers to grow high-value early season crops in greenhouses. Regarding capital costs, they are related to farm size, varying from around a minimum value of MKD3,080 for smaller farms up to a maximum value of MKD360,305. Since farm size is actually measured by observing the total cultivated acreage, this explains why the total farm size ranges from 0.05 ha to 3.5 ha. The overall cost of the most important inputs for vegetable production vary from MKD3,760 up to MKD1,550,500. The highest proportion of this belongs to seed cost $(34 \%)$, followed by fertilizers $(25 \%)$ and chemicals (17\%) (Figure 1). Of special relevance in this study is the land fragmentation indicator, the Simpson index. From 112 observations for the period 2004-07 for each of the 28 farms studied, the fragmentation level varies from total land consolidation (0) to very high land fragmentation of 0.91 , with a mean value of 0.43 .

Figure 2 reveals that around one-third of farmers cultivate on consolidated land or land with a low level of fragmentation. The explanation for this is the close relationship between total farm size and the number of cultivated plots. However, the remaining farms that were 
Table 4. Descriptive statistics for variables used in production function.

\begin{tabular}{|c|c|c|c|c|c|}
\hline Descriptive statistics of variables used & Mean & Median & Standard deviation & Min & Max \\
\hline Output (MKD) & 406,778 & 310,380 & $430,257.25$ & 13,000 & $2,710,800$ \\
\hline Capital services (MKD) & $43,742.3$ & $28,791.57$ & $49,565.36$ & 3,080 & 360,305 \\
\hline Land (ha) & 0.88 & 0.75 & 0.73 & 0.05 & 3.5 \\
\hline Simpson index & 0.43 & 0.5 & 0.32 & 0 & 0.92 \\
\hline Other inputs (MKD) & 119,272 & 67,853 & $178,618.19$ & 3,760 & $1,550,500$ \\
\hline Labour (MKD) & $70,370.9$ & 60,175 & $50,454.17$ & 7,050 & 290,700 \\
\hline Dummy variable (= 1 if greenhouse is owned) & 0.21 & 0 & 0.41 & 0 & 1 \\
\hline
\end{tabular}

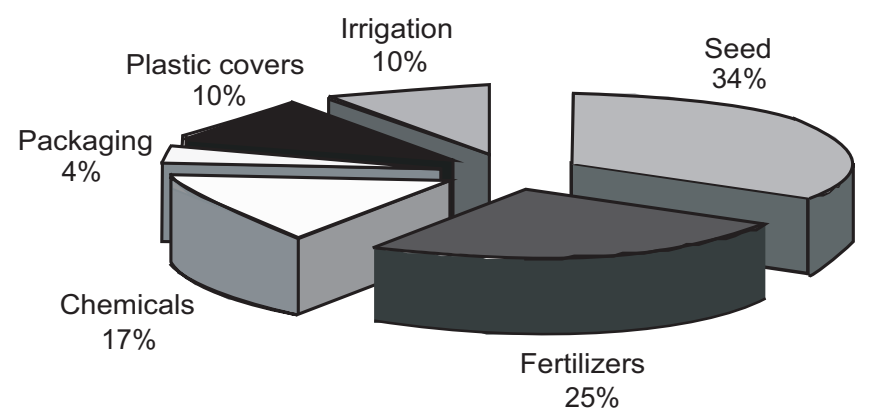

Figure 1. 'Other' material inputs.

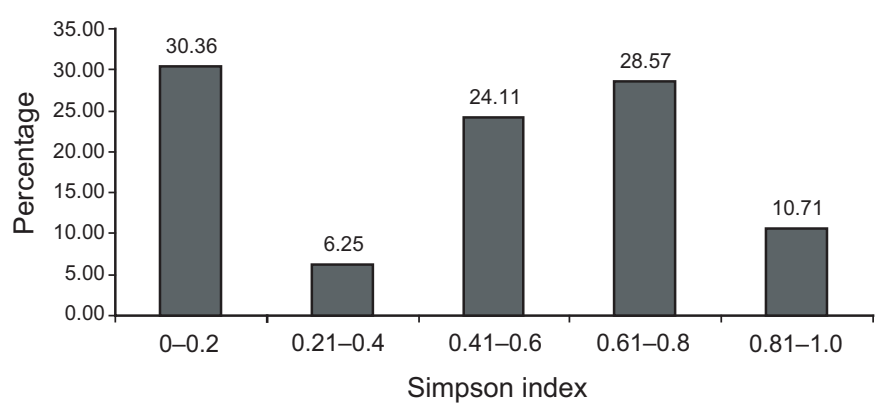

Figure 2. Percentile of households' relationship with the Simpson index.

observed operated on relatively fragmented farms (Table 5). The fragmentation index is relatively high for all observed farms except for the first group, due to the relationship between farm size and acreage. The fragmentation level is high for the smaller farms, with a decline in the largest category. The average farm plot size is increasing as farm size increases. However, there is another exception in the fifth group (2.01-2.5), in which the mean plot size is 0.2 , with 11 plots on average. Consequently, these results support the theory that the larger farms tend to cultivate at a higher level of fragmentation. The average parcel size of 0.29 ha is similar to the 0.3 ha reported by Swinnen et al (2004).

\section{Parameter estimates}

In order to estimate the impact of land fragmentation on vegetable production and to model the actual vegetable production in the Skopje and Southeastern regions of Macedonia, an Ordinary Least Square (OLS) method was applied to equations (1) and (3). The CD model was estimated in double logarithmic form. The left-hand side of Table 6 displays the results from the estimated CobbDouglas model, which yields an $R^{2}$ of 0.77 . Land fragmentation is found to have a negative but insignificant impact upon the total value of production per vegetable farm. As expected, land has a positive but insignificant impact on the value of production. The main reason for this may be due to the fact that most of the observed farms cultivate a similar acreage. Hence, the economic impact of the area of available land is probably not a decisive factor and difficult to estimate. By increasing the level of other inputs by $10 \%$, the total average value of vegetable production increases by $6.1 \%$. Similar marginal effects, given an increase of $10 \%$, are: $1.8 \%$ from capital services and $1.5 \%$ from labour.

Since the CD model formulation reveals that land fragmentation does not significantly affect vegetable production, estimation of the GLM model provides an alternative model specification, bearing in mind that the relationship between the dependent and the explanatory variables is complex in the presence of land

fragmentation. The estimation results for the GLM model are presented on the right-hand side of Table 6. The model yields a similar goodness of fit to that of the CD function $\left(R^{2}=0.75\right)$. The results reveal that land fragmentation represented by the Simpson index influences the income from growing vegetables negatively and it is statistically significant at the $10 \%$ level. Even though land in this model displays a negative impact on total vegetable production, it is still not statistically significant. This result seems to indicate that for vegetable farms in the study area, land does not appear to play a crucial role in the total value of production. This is supported by the statistically significant dummy variable for greenhouse technology, affecting the total value of production with a magnitude of MKD129,726.70 (around 32\%). Since the application of modern technologies is more limited when land parcels are fragmented, the coefficient for capital services shows a positive and statistically significant impact on vegetable production. As expected, the remainder of the variables used in the regression analysis, such as 'other inputs' and 'labour', are found to be positive and statistically significant.

In order to understand the effect that fragmentation 
Table 5. Land fragmentation results from data obtained.

\begin{tabular}{|c|c|c|c|c|}
\hline $\begin{array}{l}\text { Farm structure } \\
\text { by size (ha) }\end{array}$ & $\begin{array}{c}\text { Number of } \\
\text { observations }\end{array}$ & $\begin{array}{l}\text { Mean plot } \\
\text { size }\end{array}$ & $\begin{array}{l}\text { Mean number } \\
\text { of plots }\end{array}$ & $\begin{array}{c}\text { Mean of } \\
\text { fragmentation index }\end{array}$ \\
\hline $\begin{array}{l}\leq 0.5 \\
0.51-1.0 \\
1.01-1.5 \\
1.51-2.0 \\
2.01-2.5 \\
>2.51\end{array}$ & $\begin{array}{r}50 \\
24 \\
20 \\
7 \\
8 \\
3\end{array}$ & $\begin{array}{l}0.18 \\
0.26 \\
0.31 \\
0.41 \\
0.2 \\
0.69\end{array}$ & $\begin{array}{c}1.56 \\
3.29 \\
3.9 \\
4 \\
11 \\
5.67\end{array}$ & $\begin{array}{l}0.2 \\
0.6 \\
0.59 \\
0.5 \\
0.88 \\
0.68\end{array}$ \\
\hline Total & 112 & 0.29 & 3.28 & 0.43 \\
\hline
\end{tabular}

Table 6. Results from regression analysis for specified models.

\begin{tabular}{lcccc}
\hline Estimates & \multicolumn{2}{c}{ Cobb-Douglas model } & \multicolumn{2}{c}{$\begin{array}{c}\text { General linear model } \\
\text { t-statistics }\end{array}$} \\
Capital services & $0.18^{* *}$ & t-statistics & $2.83^{* * *}$ & 3.72 \\
Land & 0.04 & 2.00 & $-2,123.16$ & -0.05 \\
Land Simpson index & -0.13 & 0.53 & - & - \\
Simpson index & - & -0.71 & $-163,217.39^{*}$ & -1.92 \\
Other inputs & $0.61^{* * *}$ & - & $1.23^{* * *}$ & 5.31 \\
Labour & $0.15^{*}$ & 8.80 & $1.52^{* * *}$ & 2.76 \\
Dummy (greenhouse) & $0.33^{* * *}$ & 1.66 & $129,726.70^{* *}$ & 2.29 \\
Constant & $2.28^{* * *}$ & 2.39 & $88,935.44^{* *}$ & 1.97 \\
$R^{2}$ & 0.77 & 2.47 & 0.75 & 0.73 \\
Adjusted $R^{2}$ & 0.75 & & 112 & \\
Number of observations & 112 & & & \\
\hline
\end{tabular}

Notes: Cobb-Douglas variables are logarithms. ${ }^{*}$ Significant at $10 \%$ level; $* *$ significant at $5 \%$ level; ${ }^{* * *}$ significant at $1 \%$ level.

has on farm profitability and productivity, the magnitude of the impact is calculated. In the study area, the average income from vegetables is MKD406,777.62, whereas the average farm size and Simpson index are 0.88 ha and 0.43 respectively. From the estimates of the GLM regression analysis, it is clear that fragmentation affects production negatively, with an average impact of MKD163,217.39. This indicates that at 2007 prices, vegetable production increases by $7.06 \%$ if the degree of fragmentation is reduced from 0.43 to 0.2 - that is, very low fragmentation. This shows that land fragmentation may be an important factor in terms of future policy implications.

\section{Policy options}

Improvements in farmer livelihood require an increase in income, which in turn can be improved by input use efficiency. But this is less feasible for households with fragmented land. Hence, land parcel consolidation that is socially acceptable and economically reasonable may promote agriculture in the study area. The results reveal that land is of somewhat less importance since greenhouse technology provides an opportunity to achieve a higher income due to early season vegetable production. In addition, due to the relatively high level of fragmentation for larger farms, land fragmentation is to some extent indirectly chosen by farmers as a result of expanding their total acreage. In terms of demand-side causes, this may well be in disagreement with land consolidation programmes.

Wan and Cheng (2001) suggest land leasing to overcome land fragmentation in China. They also argue in favour of subcontracting cultivation rights. However, this process is not easy because sometimes the land parcel is situated in the middle of the field, which may be quite small or not connected to others. The extension service may be an appropriate government agency to establish and support consolidation efforts. Land exchange may be a better alternative, but economic analyses are required to produce the knowledge for such an exchange. Policy options such as credit assistance may be proposed to speed up land exchange.

Introducing a law to control land fragmentation is also an option (Niroula and Thapa, 2005). Any parcel of land that corresponds to less than one unit of the standardized area set by the government should be considered as fragmented and should not be transferred. But a strong legal framework must be present. Moreover, imposition of high taxes on inherited land might also mitigate land fragmentation. However, an attempt to implement this measure may also be difficult due to resistance from landholders.

Cooperative farming is considered an effective way of 
overcoming some of the negative effects of land fragmentation (Rahman and Rahman, 2008).

Consolidation of small and fragmented farms into an economically operational unit may transform the agrarian economy and overcome the obstacles to efficiency, improved productivity and efficient utilization of labour and modern agricultural technologies. Nevertheless, proper incentive structures become increasingly important in this case. Economic analysis of the individuals involved in these collective efforts is required to characterize the differences in incentive structures.

A lack of judicial land records and a lack of the required technical skills on the part of government officials may also constitute a major impediment to successful land consolidation. However, in May 2010, the World Bank supported the Cadastre and Land Policy reforms in Macedonia by approving a grant of US $\$ 12.1$ million (World Bank, 2010). The purpose of this project is to 'help finance digitizing the existing cadastre maps and plans and provide this graphical information to citizens, the private sector, and the public sector over the internet'. An efficient cadastre system and developed land market tend to improve the strategic processes needed for implementation of land consolidation schemes. If any of the above stated policy options are to be achievable, consolidation programmes ought to be characterized by appropriate motivation, institutional resilience and suitable infrastructure and, most importantly, the users should be directly involved in the process.

\section{Concluding remarks}

The objective of this study was to determine whether land fragmentation influenced production. One of the main findings is that, irrespective of the negative impact that land fragmentation has upon vegetable production, the technology used by farmers tends to mitigate any negative effects. Furthermore, according to Swinnen et al (2004), 'Macedonian farmers are used to land fragmentation and most of them do not feel troubled by the fact that they cultivate many small sized parcels', and 'Farmers feel comfortable cultivating their family land and are used to its fragmentation'. This observation is confirmed by the result that land is not such an important input in vegetable production as the opportunity of using greenhouse technology, which increased income by around $32 \%$.

Although this study focused on vegetable growers in Macedonia, the results may have a wider applicability in many developing countries where land fragmentation is an important problem. Most studies regarding land fragmentation do not report on the magnitude of the economic impact, which was found to be $7.06 \%$ in this study. Furthermore, the role of specific technologies that may mitigate the negative impact of land fragmentation is not considered. However, most of the studies conducted in Asia regarding land fragmentation examine rice production (Wan and Cheng, 2001; Wu et al, 2005; Tan, 2005; Parikh and Shah, 1994; Wadud and White, 2000). Hence, the design of future policies to facilitate land consolidation should be carefully chosen according to the local conditions, specific technologies available, type of crop that is grown, and most importantly the existence of a functioning property rights system.

\section{Acknowledgments}

The authors are grateful to Aleksandra MartinovskaStojceska from the Institute of Agricultural Economics at the Faculty of Agricultural Sciences and Food, Skopje, Macedonia, and Professor Yves Surry, Department of Economics, Swedish University of Agricultural Sciences, Uppsala, for providing valuable comments and suggestions. This document has been produced with the financial assistance of the Swedish International Development Cooperation Agency (SIDA). The views herein shall not necessarily be taken to reflect the official opinion of SIDA.

\section{References}

Bentley, J.W. (1987), 'Economic and ecological approaches to land fragmentation: in defense of a much-maligned phenomenon', Annual Review of Anthropology, Vol 16, pp 31-67.

Blaikie, P.M., and Sadeque, S.Z. (2000), Policy in the High Himalayas: Environment and Development in the Himalayan Region, ICIMOD, Kathmandu.

Blarel, B., Hazell, P., Place, F., and Quiggin, J. (1992), 'The economics of farm fragmentation: evidence from Ghana and Rwanda', World Bank Economic Review, No 6, pp 233-254.

Chen, X., Ender, P.B., Mitchell, M., and Wells, C. (2011), Stata Web Books: Regression With Stata, UCLA Academic Technology Services, website: http://www.ats.ucla.edu/stat/stata/webbooks/ reg/.

FAO (2008), Land Resources and People: Dependence and Interaction, website: http://www.fao.org/DOCREP/004/X3810E/ x3810e04.htm\#g.

Fenoaltea, S. (1976), 'Risk, transaction cost and the origin of medieval agriculture', Exploration in Economic History, Vol 13, pp $129-151$.

Ilbery, B.W. (1984), 'Farm fragmentation in the Vale of Evesham', Area, Vol 16, No 2, pp 159-165.

Jabarin, A.S., and Epplin, F.M. (1994), 'Impact of land fragmentation on the cost of production wheat in the rain-fed region of northern Jordan', Agricultural Economics, Vol 11, pp 191-196.

MAFWE - Ministry of Agriculture, Forestry and Water Economy (2007), Annual Agricultural and Rural Development Report for 2007, Skopje, Macedonia.

McPherson, M.F. (1982), Land Fragmentation: A Selected Literature Review, Development Discussion Paper No 141, Harvard Institute for International Development, Harvard University, Cambridge, MA.

Melmed-Sanjak, J., Bloch, P., and Hanson, R. (1998), Project for the Analysis of Land Tenure and Agricultural Productivity in the Republic of Macedonia, Working Paper No 19, Land Tenure Center, University of Wisconsin, Madison, WI.

Milanov, M., and Martinovska-Stojceska, A. (2002), 'Cost and calculations in the agriculture', Faculty for Agricultural Sciences and Food, Skopje.

NBRM - National Bank of the Republic of Macedonia (2011), website: http://www.nbrm.mk/; official foreign exchange rates on 8 December 2011: http://www.nbrm.mk/defaulten.asp?pmenu=kurslistENIKL.

Niroula, G.S., and Thapa, G.B. (2005), 'Impacts and causes of land fragmentation, and lessons learned from land consolidation in South Asia', Land Use Policy, Vol 22, pp 358-372.

Parikh, A., and Shah, K. (1994), 'Measurement of technical efficiency in the North-West frontier province of Pakistan', Journal of Agricultural Economics, Vol 45, pp 132-138.

Rahman, S., and Rahman, M. (2008), 'Impact of land fragmentation and resource ownership on productivity and efficiency: the case of rice producers in Bangladesh', Land Use Policy, Vol 26, pp 95-103. 
Sherlund, S.M., Barrett, C.B., and Adesina, A.A. (2002), 'Smallholder technical efficiency controlling for environmental production conditions', Journal of Development Economics, Vol 69, pp 85-101.

Swinnen, J.F.M., Noev, N., and Vranken, V. (2004), The Development of Land Rental Markets in Bulgaria and the Former Yugoslav Republic of Macedonia, Working Paper 2004/1, Research Group on Food Policy, Transition, and Development, Katholieke Universiteit, Leuven

Tan, S. (2005), 'Land fragmentation and rice production: a case study of small farms in Jiangxi Province, China', PhD thesis, Wageningen University, Wageningen.

Wadud, M., and White, B. (2000), 'Farm household efficiency in Bangladesh: a comparison of stochastic frontier and DEA methods', Applied Economics, Vol 32, pp 1665-1673.

Wan, G., and Cheng, E. (2001), 'Effects of land fragmentation and returns to scale in the Chinese farming sector', Applied Economics, Vol 33, pp 183-194.

Wu, Z., Liu, M., and Davis, J. (2005), 'Land consolidation and productivity in Chinese household crop production', China Economic Review, Vol 16, pp 28-49.

World Bank (2010), ‘World Bank supports Cadastre and Land Policy reforms in FYR Macedonia', press release, website: http://go.worldbank.org/HXSPDUV4S0.

\section{Appendix}

Table A1. Depreciation rates of farm assets.

Ordinal Name
number

Annual depreciation rate $(\%)$

$1 \quad$ Buildings and other structures Production of early season vegetables and fruits 7

2 Equipment for establishing activities from vegetable, fruit and vine-growing production as well as providing farm services Single-axle tractors plus accessories Seeding and crop nursing equipment Cleaning, sorting and packaging equipment Disc harrows, sprinklers, fertilizer and chemical distributing equipment

Source: Milanov and Martinovska-Stojceska (2002). 